This item was submitted to Loughborough's Research Repository by the author.

Items in Figshare are protected by copyright, with all rights reserved, unless otherwise indicated.

\title{
Analysis of pulsed electroplasticity in metals
}

PLEASE CITE THE PUBLISHED VERSION

https://doi.org/10.1109/PPC.2017.8291317

PUBLISHER

IEEE

VERSION

AM (Accepted Manuscript)

LICENCE

CC BY-NC-ND 4.0

\section{REPOSITORY RECORD}

Coles, Laurence A., Anish Roy, Vadim V. Silberschmidt, Bucur M. Novac, Faisal T. Alotaibi, Peter Senior, and Ivor R. Smith. 2019. "Analysis of Pulsed Electroplasticity in Metals". figshare.

https://hdl.handle.net/2134/32573. 


\title{
ANALYSIS OF PULSED ELECTROPLASTICITY IN METALS
}

\author{
L.A. Coles ${ }^{\xi}$, A. Roy, V.V. Silberschmidt, B.M. Novac, T. Alotaibi, P. Senior, I.R. Smith \\ Wolfson School of Mechanical, Electrical and Manufacturing Engineering, Loughborough University \\ Loughborough, Leicestershire LE11 3TU, UK
}

\begin{abstract}
Application of high-intensity electric fields and/or currents is known to enhance materials' deformability. For instance, their continuous or in short-pulses application on metals and ceramics may significantly affect their deformation response to external loads. This phenomenon is commonly referred to as electroplasticity (EP) or electroplastic effect.

In the present preliminary study, mechanical tensile experiments were carried out in combination with the application of short duration high-intensity electric currents in copper samples. Our study captures the enhanced plasticity induced in the metal due to EP. Postevent microstructural studies highlighted the effect of high-intensity electric current on the material.
\end{abstract}

\section{INTRODUCTION}

Mechanisms of plastic deformation and their realisation in metals and alloys have been extensively studied in the past decades. Extrinsic factors known to influence kinetics of plastic flow are temperature, loads and loading rate. These factors are usually fine-tuned for tailoring of metals processing in most modern manufacturing techniques.

An interesting approach to enhance materials' deformability is the use of high-intensity electric fields. Experiments indicate that these fields have a significant positive effect on plastic deformation, especially when acting concurrently with more common extrinsic factors mentioned above. For instance, a high-density electric current applied continuously (CC: continuous current) or in short pulses (PC: pulsed current) on metals and ceramics significantly affected their deformation response to external loads. Studies in an $\mathrm{Al}$ alloy with a nominal intensity of a DC electrical field produced the following effects [1]: (a) reduction of flow stress by $10-20 \%$; (b) increase in a strain-rate-hardening exponent; (c) retardation of grain growth. The tests indicated that the influence of the electric field tended to increase with a decrease in grain size. Other studies showed smoothing of material surfaces [2] and recrystallization [3]. EP is known to affect the apparent hardness (HV) of components after fracture (i.e. fracture surfaces demonstrated different $\mathrm{HV}$ values when compared to those without the EP effect). There are several reported mechanisms for EP including (i) electron-wind forces, i.e. exertion of a force on dislocations by drifting electrons enhancing their motion; (ii) Joule heating caused by concentration of electrons circumventing defects, and (iii) thermal compressive stress initiated by high-speed heating by electrical pulses, which affect plasticity and deformation [4].

Here, we present some of our preliminary results demonstrating the EP effect in copper carried out with a designed and developed special setup in-house.

\section{EXPERIMENTAL SETUP AND RESULTS}

The source of energy is a pulsed power arrangement consisting of a capacitor bank triggered by a mechanically-operated closing switch. The bank has the following specifications: $\mathrm{C}=2.4 \mathrm{mF}, \mathrm{L}=240 \mu \mathrm{H}, \mathrm{R}=$ $110 \mathrm{~m} \Omega$. Typical current waveforms are shown in Fig. 1. The currents are measured with an electronicallyintegrated Rogowsky coil.

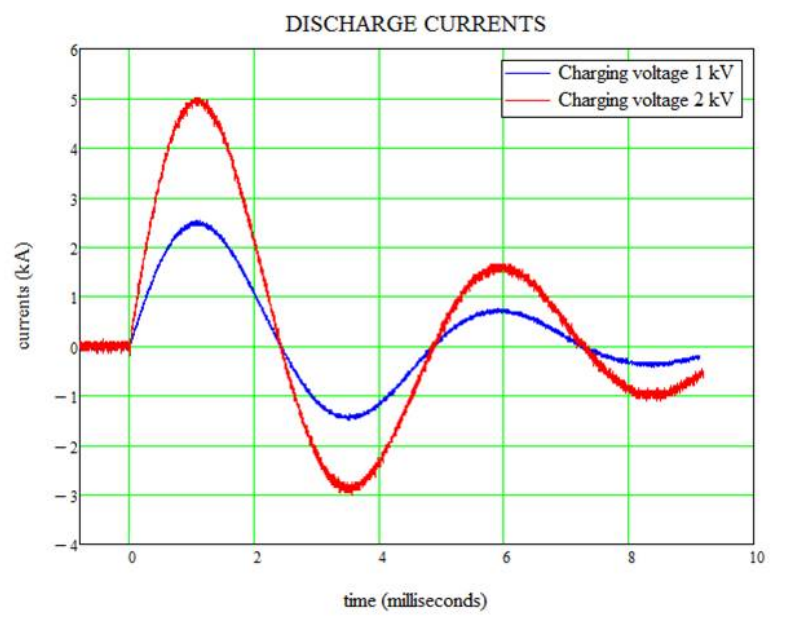

Figure 1. Typical current waveforms for various charging voltages.

\footnotetext{
६ email: L.A.Coles@lboro.ac.uk
} 
The current variation was repetitive and consistent for multiple tests.

A copper wire with a nominal diameter of $0.8 \mathrm{~mm}$ was used for our experimental studies. The wire was initially tested in a tensile testing machine to assess its mechanical properties. The tests indicated that at a load of $\sim 113 \mathrm{~N}$ the material yielded, this corresponds to a stress of $\sim 225$ MPa. To perform experiments under the influence of electric fields, the copper wires were looped over two stainless-steel connectors, fixed to two nylon ropes that electrically isolated the specimens from the rest of the experimental setup. The power leads were then soldered directly onto the copper wire (Fig. 2). The lower nylon rope was used to suspend a weight of $10 \mathrm{~kg}(=98 \mathrm{~N})$ to induce a pre-stress in the wire prior to EP testing. The load imposed was much lower than the load to induce yield hence, the pre-stress was well within the elastic limit of the material.

Different current densities were applied with a discharge current presented in Fig. 1. For each of the studied current densities, the number of pulses to failure was assessed (Table 1). A current density $\geq 5125 \mathrm{~A} / \mathrm{mm}^{2}$ caused sufficient EP induced deformation in the copper sample leading to failure in a single pulse. Multiple pulses were required to cause failure at a current density of 4750 $\mathrm{A} / \mathrm{mm}^{2}$. With a current density of $4025 \mathrm{~A} / \mathrm{mm}^{2}$, slight elongation was observed indicating some plastic flow, but following 8 pulses no tensile failure was observed.

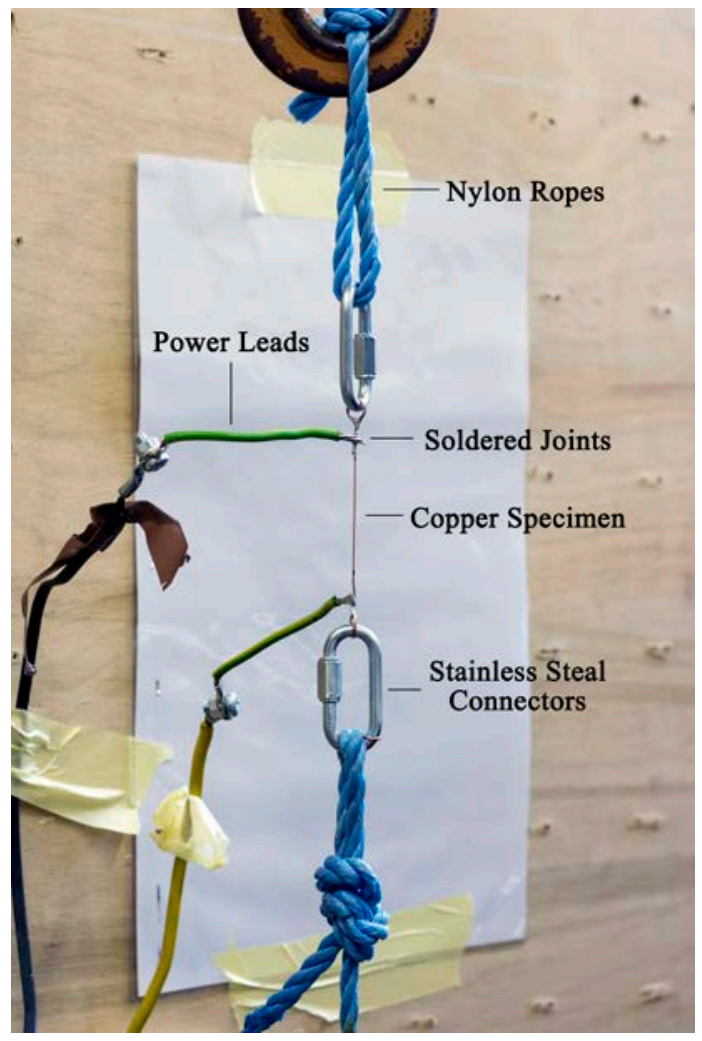

Figure 2. Experimental setup for EP with copper wire and leads to transmit electrical power.
Table 1. Effect of current density on specimen

\begin{tabular}{|c|c|c|}
\hline $\begin{array}{c}\text { Capacitor bank } \\
\text { voltage } \\
\text { (kV) }\end{array}$ & $\begin{array}{c}\text { Current } \\
\text { density } \\
\left(\mathbf{A} / \mathbf{m m}^{\mathbf{2}}\right)\end{array}$ & $\begin{array}{c}\text { Number of } \\
\text { pulsed to } \\
\text { failure }\end{array}$ \\
\hline 1.2 & 5500 & 1 \\
\hline 1.1 & 5125 & 1 \\
\hline 1.0 & 4750 & 3 \\
\hline 0.9 & 4025 & 8 with no failure \\
\hline
\end{tabular}

\section{DISCUSSION}

The microstructure of the studies copper specimens was assessed before any experimentation (virgin state) and after EP; for comparison, the microstructure obtained after purely mechanical testing to failure is also presented (Fig. 3). The results show some interesting perspective on EP. First, as expected, the grain sizes after mechanical testing are smaller (Fig. 3(b)) when compared to both the virgin state (Fig. 3(a)) and EP (Fig. 3(c)) specimens; this is due to elongation of the wire which led to lateral contraction of grains due to the Poisson's effect. Interestingly, the grain size in Fig. 3(c) show much lower contraction. These grains are clearly larger than those in Fig 3(b), indicating that EP induced deformations were instantaneous, leading to specimen failure without necking.

These results demonstrate the EP effect varies greatly with the imposed current density. By appropriately adjusting the current density, plastic flow may be controlled in the material without the need for higher mechanical loads. The additional benefit of instantaneous deformation is also important in maintaining the original microstructure of the material.

\section{CONCLUDING REMARKS}

Our preliminary tests for proof-of-concept electroplasticity applications show the potential of inducing plastic deformations in metals without the use of purely mechanical loads. The capability of maintaining the initial microstructure allows for new possibilities in metal forming, which are yet to be fully exploited in the industry.

\section{V.REFERENCES}

[1] H. Conrad, W. Cao, X. Lu, A. Sprecher. "Effect of an electric field on the superplasticity of $7475 \mathrm{Al}$ ", Scripta Metall., 23, 697 (1989).

[2] H. Conrad, J. White, W.D. Cao, X.P. Lu, A.F. Sprecher. "Effect of electric current pulses on fatigue characteristics of polycrystalline copper". Mater. Sci. Eng. A: Struct., 145, 1-12. (1991)

[3] Z.J. Wang, H. Song. "Effect of high-density electropulsing on microstructure and mechanical 
properties of cold-rolled TA15 titanium alloy sheet” J. Alloy Compd., 470, 522-530. (2009)

[4] RS Qin. 2015; Mater Sci Tech Ser 31(2)
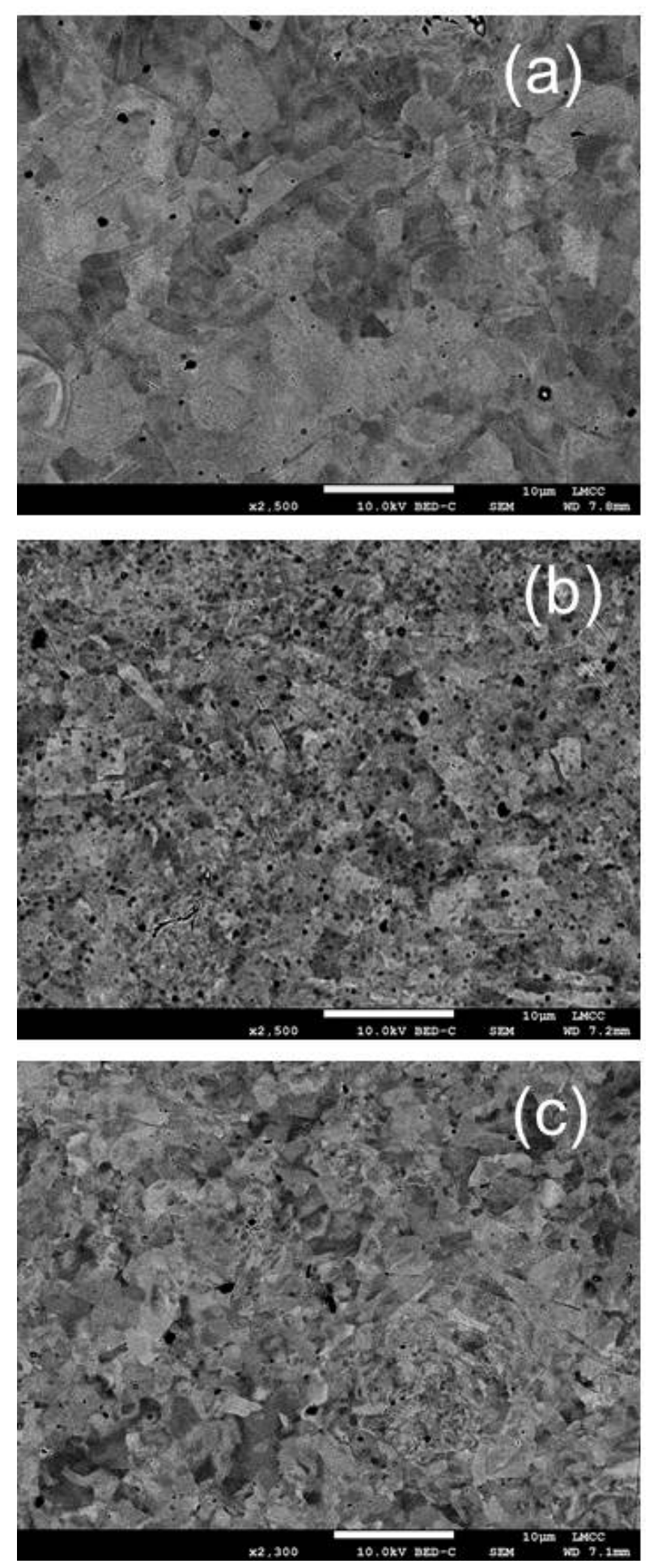

Figure 3. Microstructural assessment of copper samples:

(a) virgin state; (b) fracture surface after mechanical testing to failure; (c) fracture surface of failed samples in EP testing. 